\title{
THE USEFULL OF AUGMENTED REALITY OVER THE NATIONAL INSIGHT IN LEARNING ERA DISRUPTION-BASED
}

\section{Eliya Rochmah, Erna Labudasari, Nurani Amalia}

Universitas Muhammdiyah Cirebon

eliyarochmah77@gmail.com

\section{Article History}

accepted 09/07/2018

approved 01/08/2018

published 17/09/2018

\section{Keywords}

national insight, learning, disruption

\begin{abstract}
Technological progress greatly affects all areas of human life, including in the field of Education. One use of technology in education that can be used is augmented reality that displays a virtual world into a real form that can be more easily understood and fun. Augment reality is used in learning history that is displayed in real way so it can facilitate students in learning. This technology is used to solve problems in learning that students feel bored with learning history that only uses lecture and discussion methods so that students are not eager in learning. In the face of this technological progress is utilized as an innovative form based on disrupsi era so that students can learn history more easily and can appreciate the services of heroes and not forget the history of the nation along with the times. The study was conducted at SDN Kanggraksan class $V B$ with learning outcomes experienced improvement in each cycle.
\end{abstract}

Social, Humanities, and Education Studies (SHEs): Conference Series https://jurnal.uns.ac.id/shes

p-ISSN 2620-9284

e-ISSN 2620-9292 


\section{PENDAHULUAN}

Pesatnya kemajuan teknologi informasi saat ini menjadi sesuatu yang tidak dapat dihindarkan dari kehidupan manusia. Pada zaman yang serba canggih ini penggunaan teknologi begitu sangat dibutuhkan dalam membantu kegiatan manusia baik dalam segi teknologi industri, maupun teknologi yang kini mulai digunakan dalam membantu proses pembelajaran di sekolah. Menurut Gardiner dkk (2017:13) Negara-negara maju, yang selama ini menjadi pusat perkembangan ilmu pengetahuan dan teknologi, menghadapi perubahan yang melaju deras tak tertahankan dan tidak gampang diatasi dengan instrumen yang ada hari ini diperkirakan, sistem pendidikan tinggi Indonesia pun akan menghadapi perubahan disruptif menjungkirbalikkan sistem yang berlaku hingga akhirnya terjadi perubahan mendasar dalam keseluruhan sistem pendidikan. Kemajuan teknologi ini menjadi sebuah tantangan tersendiri bagi dunia pendidikan untuk dapat berkembang mengikuti perkembangan teknologi dunia.

Tujuan pendidikan nasional Indonesia merupakan implementasi dari empat pilar UNESCO yaitu: Learning to know (belajar untuk menguasai pengetahuan), learning to do (belajar untuk mengetahui keterampilan), learning to be (belajar untuk mengembangkan diri), dan Learning to live together (belajar untuk hidup bermasyarakat), untuk dapat mewujudkan empat pilar pendidikan di era globalisasi informasi sekarang ini, guru sebagai inovator dalam pembelajaran perlu menguasai dan menerapkan teknologi dalam pembelajaran (Triyanto, dkk: 2013). Oleh karena itu perlu adanya inovasi untuk mewujudkannya.

Inovasi pada aktivitas kegiatan pembelajaran ditentukan oleh kreatifitas seorang guru yang merupakan tonggak utama di kelas. Guru di sekolah memiliki peran sebagai fasilitator, pembimbing dan inovator yang sangat menentukan bagaimana hasil belajar peserta didik di dalam kelas. Seiring dengan kemajuan teknologi yang pesat, seharusnya menjadi tantangan bagi seorang guru untuk menguasai teknologi pendidikan yang dapat memudahkan dalam mencapai tujuan pembelajaran.

Umam dan Ely (dalam Padmini, 2015) menyatakan bahwa potensi teknologi pendidikan dapat (1) meningkatkan produktivitas pendidikan dengan mempercepat tahap belajar, (2) memberikan kemungkinan pelajar untuk belajar secara mandiri, (3) memberikan dasar yang lebih ilmiah terhadap pembelajaran, (4) lebih memantapkan pembelajaran, (5) memungkinkan untuk belajar (mengakses materi) dengan cepat, dan (6) memungkinkan penyajian pembelajaran yang lebih luas. Namun, potensi tersebut ternyata belum sepenuhnya dimanfaatkan oleh banyak praktisi pendidikan.

Penggunaan teknologi masih sebagian kecil digunakan padahal jika seorang guru tidak mau belajar untuk mempelajari lebih dalam mengenai teknologi maka dengan kemajuan teknologi yang semakin pesat akan jauh tertinggal oleh negara lain. Guru tidak mampu menjadi inovator dan fasilitator dalam membantu peserta didik memahami pembelajaran dengan lebih mudah dan menyenangkan, sehingga masih banyak ditemukan masalah dalam pembelajaran di kelas karena guru belum memaksimalkan pengunaan teknologi atau media yang dapat memudahkan Peserta didik untuk belajar.

Salah satu permasalahan yang muncul dalam pembelajaran yaitu pengenalan sejarah tentang tokoh pahlawan dalam mata pelajaran IImu Pengetahuan Sosial (IPS) di SDN Kanggraksan kelas VB yaitu dari hasil wawancara dengan beberapa Peserta didik sebagian besar Peserta didik merasa bosan dan kesulitan dalam mempelajarinya. Selain materinya yang bersifat hafalan, metode pembelajaran yang digunakan oleh guru hanya ceramah dan diskusi saja sehingga belum memicu minat Peserta didik dalam belajar sehingga pembelajaran menjadi kurang menarik. Dari 30 orang Peserta didik hanya 12 orang atau 40\% yang mencapai Kriteria Ketuntasan Minimum (KKM). KKM yang ditetapkan di SDN Kanggraksan untuk mata pelajaran IPS adalah 70 . Hasil tersebut menunjukkan bahwa minat belajar Peserta didik masih sangat rendah yang 
mengakibatkan peserta didik kurang mengetahui serta mencintai tokoh pahlawan Indonesia yang telah banyak berjasa bagi negara. Indonesia Oleh karena itu diperlukan suatu pembelajaran yang menarik dan menyenangkan sehingga peserta didik dapat lebih mencintai tokoh pahlawan yang telah banyak berjasa.

Salah satu teknologi pendidikan yang dapat digunakan yaitu augmented reality yang menggabungkan objek 2D/3D ke dalam dunia nyata supaya manusia dapat berinteraksi dengan komputer secara lebih alami. Augmented reality (AR) adalah sebuah teknologi yang menggabungkan benda maya ke dalam sebuah lingkungan nyata. Teknologi ini menjadikan pembelajaran lebih menarik dan menyenangkan sesuai dengan kehidupan sehari-hari. Padmini (2015) dalam penelitiannya mengungkapkan bahwa teknologi pendidikan terbukti dapat digunakan untuk meningkatkan hasil prestasi peserta didik dan mutu pendidikan yang ada serta menciptakan proses belajar mengajar yang kreatif, inovatif, menarik dan menantang.

Di Era Disrupsi ini tentunya menjadi tantangan tersendiri untuk menguasai teknologi, terutama teknologi pendidikan yang dapat digunakan untuk mengajarkan materi kepada peserta didik, karena jika seorang pendidik tidak mampu memaksimalkan potensi teknologi maka dunia pendidikan tidak akan berkembang sesuai dengan perkembangan zaman yang telah serba menggunakan teknologi. Oleh karena itu pemanfaatan teknologi dalam pendidikan menjadi sangat penting untuk dipelajari dan digunakan dalam pembelajaran. Jika pembelajaran tentang sejarah tokoh pahlawan tidak mampu dijelaskan secara menyenangkan bagi peserta didik maka pembelajaran mengenai sejarah akan selamanya menjadi hal yang susah dan rumit untuk dipelajari tidak akan ada catatan sejarah yang mengena di hati sebagai bentuk perjuangan pahlawan pada zaman dahulu. Sejarah hanya akan menjadi kenangan yang mudah dilupakan.

\section{METODE}

Metode yang digunakan dalam penelitian adalah PTK dengan desain penelitian model spiral dari Kemmis dan Taggart yang dimulai dengan tahap perencanaan (planning), tindakan (action), pengamatan (observing), dan refleksi (reflecting) sebagai berikut.

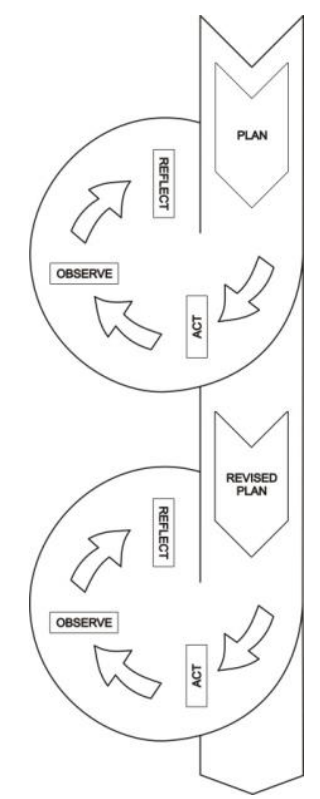

Gambar 1. Model Spiral Kemmis \& Taggart (Wiriaatmadja, 2005: 66) 
Subjek dalam penelitian ini adalah Peserta didik kelas VB SDN Kanggraksan Kota Cirebon tahun ajaran 2017/2018 dengan jumlah Peserta didik sebanyak 30 orang. Instrumen yang digunakan yaitu tes hasil belajar, format observasi, wawancara, dan catatan lapangan. Teknik pengolahan data yaitu pengolahan data proses yang terdiri dari kinerja guru dan aktivitas Peserta didik selama pembelajaran berlangsung serta pengolahan data hasil yaitu penilaian hasil belajar dengan tes menggunakan penilaian sebagai berikut.

$$
\text { Nilai }=\frac{\text { skor yang diperoleh }}{\text { skor ideal }} \times 100
$$

Tafsiran:

$\mathrm{T}$ (Tuntas) $=$ Nilai $\geq \mathrm{KKM}$

BT $($ Belum Tuntas $)=$ Nilai $<$ KKM

\section{HASIL DAN PEMBAHASAN}

Penggunaan teknologi augmented reality dalam mengenalkan tokoh pahlawan telah membantu peserta didik memahami materi pembelajaran dengan lebih mudah dan menyenangkan. Peserta didik terlihat antusias untuk belajar menggunakan teknologi augmented reality. Hal ini sesuai dengan AECT (1997) menyatakan bahwa ketersediaan sumber/media sebagai saluran dalam menyampaikan informasi belajar baik berupa manusia atau nonmanusia (hardware dan software sangat mempengaruhi proses pembelajaran (Wena, 2014:15). Cara kerja teknologi augmented reality dalam pembelajaran IPS adalah dengan mendeteksi wajah pengguna dalam hal ini adalah peserta didik kelas VB SDN Kanggraksan. Dalam proses pembelajaran, peserta didik akan diminta mengarahkan wajahnya ke arah webcam laptop yang telah terpasang media augmented reality kemudian aplikasi akan mendeteksi wajah peserta didik sebagai wajah pahlawan. Wajah peserta didik akan berubah seolah-olah menjadi wajah tokoh pahlawan. Menurut Rochmah dan Labudasari (2018), secara detail langkah pembelajaran di kelas dengan menggunakan media berbasis teknologi augmented reality adalah sebagai berikut.

1. Siswa mengarahkan wajah ke webcam laptop yang telah terpasang media augmented reality.

2. Siswa bisa mensimulasikan dan menampilkan tokoh pahlawan di wajahnya.

3. Siswa dapat mengetahui deskripsi tentang riwayat hidup dan kisah singkat perjuangan tokoh pahlawan pada saat memperjuangkan kemerdekaan.

4. Siswa dapat melihat video ilustrasi tentang tokoh pahlawan kemerdekaan. 
Berikut ini adalah tampilan halaman muka media augmented reality bermuatan wawasan kebangsaan.

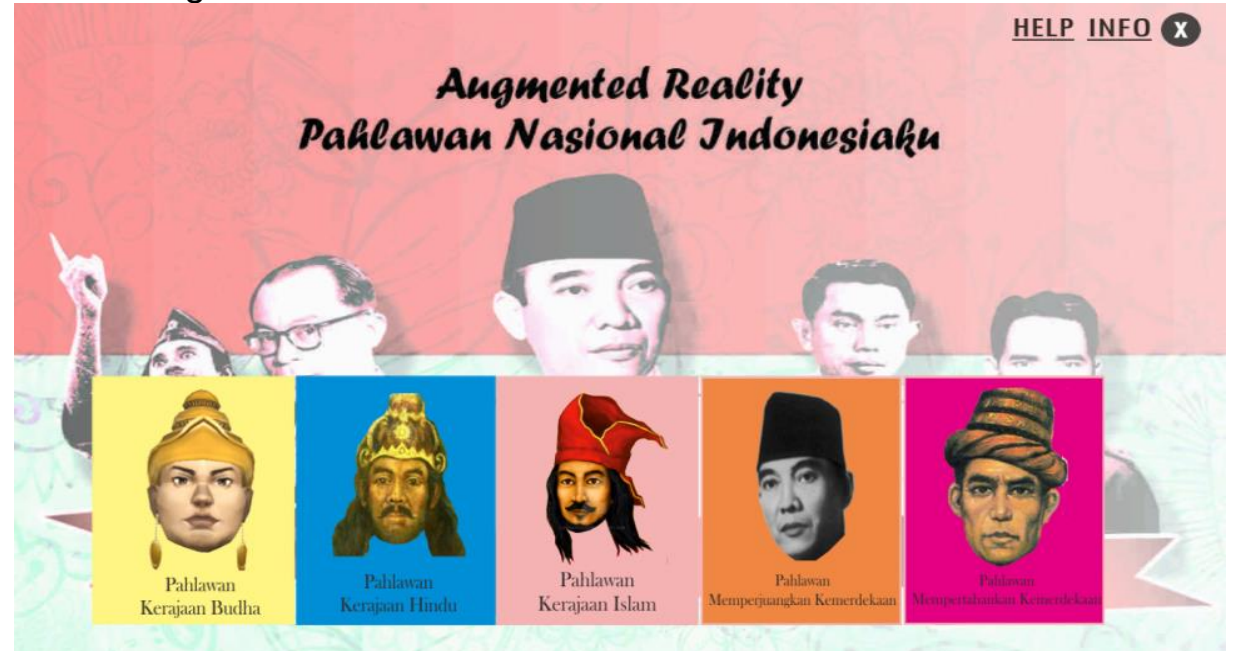

Gambar 2. Halaman Muka Media Augmented Reality Bermuatan Wawasan Kebangsaan.

\section{Pra Siklus}

Pembelajaran IPS di kelas VB SDN Kanggaraksan awalnya ditemukan bahwa minat belajar IPS peserta didik rendah. Hal ini berakibat terhadap hasil belajar juga rendah. Salah satu permasalahan yang muncul dalam pembelajaran yaitu pada materi pengenalan sejarah tentang tokoh pahlawan. Hasil wawancara dengan beberapa guru kelas dan beberapa peserta didik sebagian besar peserta didik merasa bosan dan kesulitan dalam mempelajarinya. Selain materinya yang bersifat hafalan, metode pembelajaran yang digunakan oleh guru hanya ceramah dan diskusi saja sehingga belum memicu minat Peserta didik dalam belajar. Selain itu, media pembelajaran masih bersifat text book atau menggunakan buku dan belum terintegrasi dengan teknologi seperti augmented reality sehingga pembelajaran menjadi kurang interaktif dan tidak menarik. Dari 30 orang Peserta didik hanya 12 orang atau $40 \%$ yang mencapai KKM. Hasil tersebut menunjukkan bahwa minat belajar Peserta didik masih sangat rendah yang mengakibatkan Peserta didik kurang mengetahui serta mencintai tokoh pahlawan Indonesia yang telah banyak berjasa bagi negara. Indonesia Oleh karena itu diperlukan suatu pembelajaran yang menarik dan menyenangkan sehingga Peserta didik dapat lebih mencintai tokoh pahlawan yang telah banyak berjasa. Salah satu caranya adalah dengan menggunakan media teknologi augmented reality. Teknologi augmented reality dapat diterapkan pada pembelajaran IPS pada materi tokoh kepahlawanan.

\section{Siklus I}

Pada siklus I, perlakuan yang diberikan adalah dengan menggunakan media berbasis teknologi augemented reality bermuatan wawasan kebangsaan pada materi tokoh kepahlawanan. Awalnya guru memberikan pengarahan tentang penggunaan media augmented reality. Guru membimbing dan mendampingi peserta didik selama proses pembelajaran agar kelangsungan proses pembelajaran berjalan dengan kondusif. Dengan arahan dan bimbingan dari guru, peserta didik terlihat lebih bersemangat dan auntusias selama proses pembelajaran, hal ini terlihat dari banyak siswa yang saling berebut untuk menjadi yang pertama mencoba menggunakan media 
augmented reality. Berikut ini adalah gambar proses pembelajaran yang berlangsung di kelas VB SDN Kanggraksan.

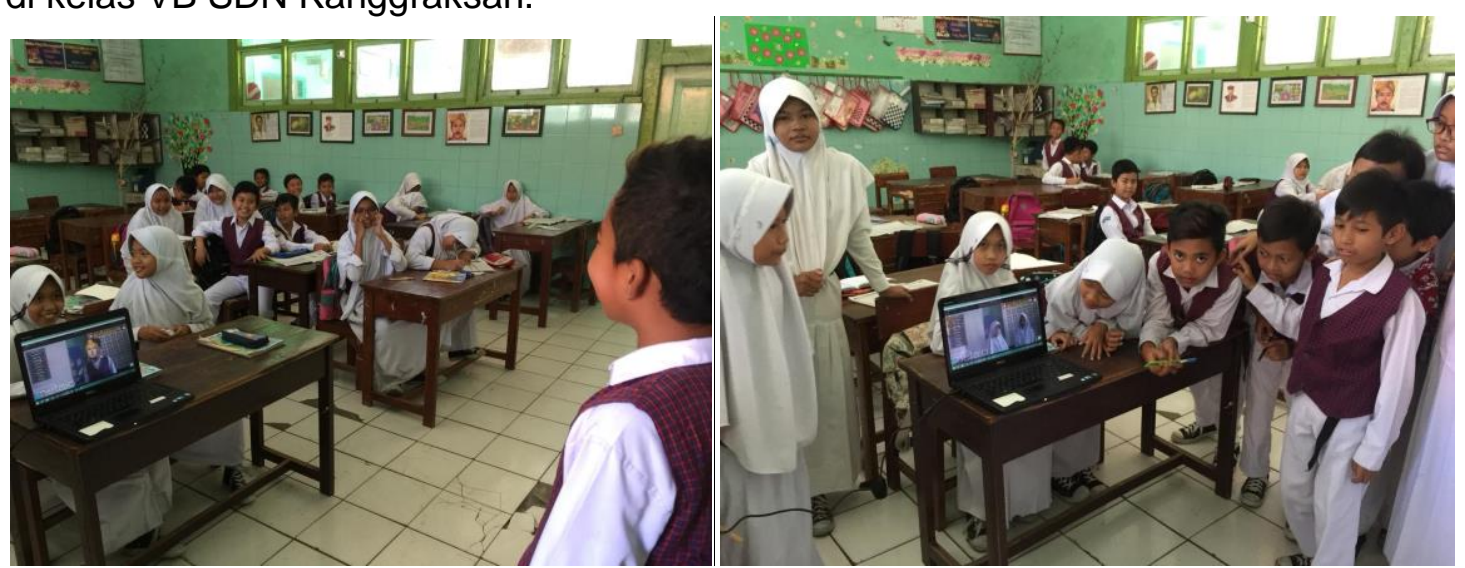

Gambar 3. Proses Pembelajaran Menggunakan Teknologi Augmented Reality

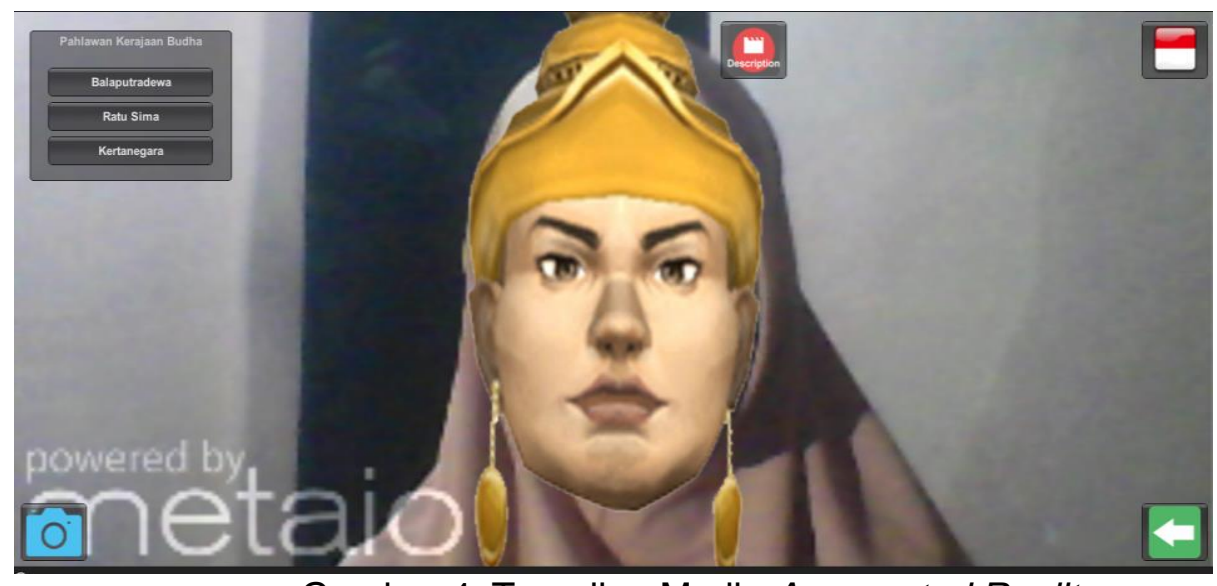

Gambar 4. Tampilan Media Augmented Reality

Hasil belajar Peserta didik yang diperoleh pada siklus I yaitu sebanyak 18 Peserta didik yang mencapai KKM atau sebanyak 60\%. Selain itu hasil kinerja guru pada siklusi I diperoleh sebanyak $85,4 \%$ menunjukkan kinerja sangat baik. Hasil tersebut telah mengalami peningkatan dibandingkan sebelum menggunakan media berbasis teknologi augmented reality. Setelah dilakukan siklus I kemudian dilanjutkan siklus II agar hasil belajar lebih maksimal.

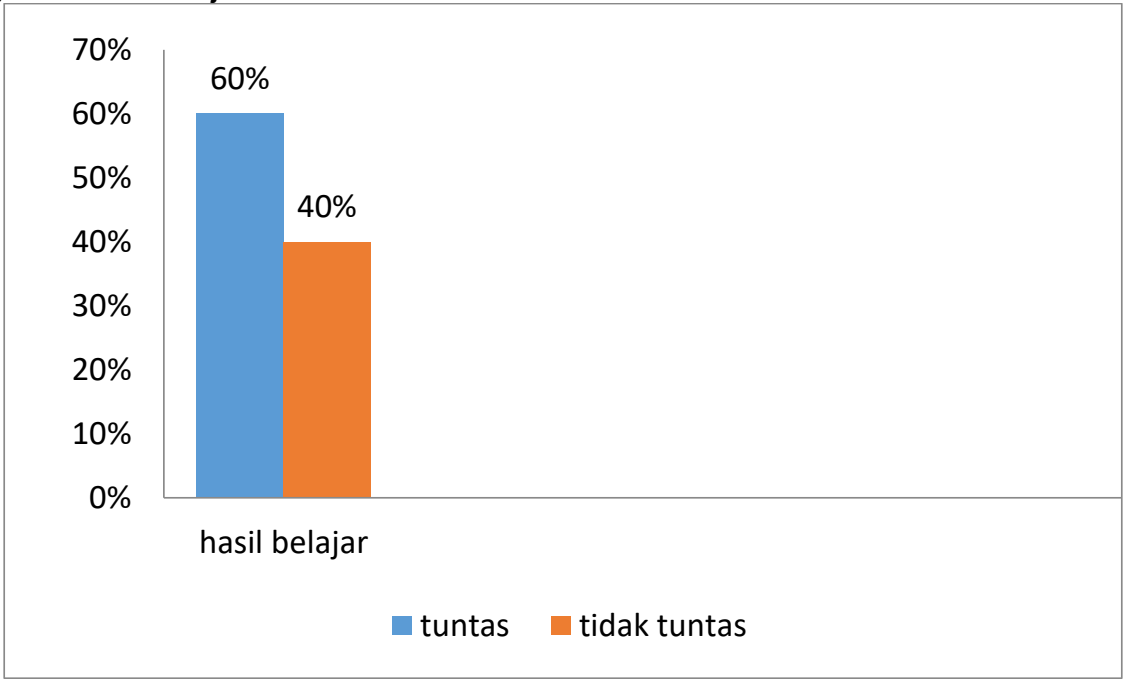

Gambar 5. Presentase Hasil Belajar Peserta didik Siklus I 
SHEs: Conference Series 1 (1) (2018) 232-239

\section{Siklus II}

Berdasarkan hasil refleksi pada siklus I, peserta didik sudah mulai terlihat antusias dalam mengikuti pembelajaran IPS namun hasil belajar yang diperoleh belum sepenuhnya memenuhi KKM. Hasil belajar yang diperoleh pada siklus I diperoleh bahwa baru $60 \%$ peserta didik yang mencapai nilai KKM, dan artinya masih 12 peserta didik lagi yang belum mencapai nilai maksimal.

Untuk mencapai nilai maksimal, peneliti memberikan tambahan perlakuan dengan belajar secara berkelompok. Dengan membentuk kelompok, siswa tidak lagi berebut untuk mencoba media augmented reality sehingga proses belajar menjadi lebih efektif dan efisien. Hasil yang diperoleh pada siklus II yaitu sebanyak 28 Peserta didik atau 93,3\% Peserta didik yang tuntas/memenuhi KKM. Selain itu, hasil kinerja guru pada siklus II sebanyak 93,7\% menunjukkan kriteria sangat baikl. Dari hasil tersebut menunjukkan bahwa pada setiap siklusnya hasil belajar Peserta didik mengalami peningkatan baik itu dari hasil tes maupun dari minat belajar Peserta didik yang terlihat lebih senang untuk belajar tokoh pahlawan menggunakan teknologi tersebut. Hal ini sesuai dengan Riset yang dilakukan oleh Ode (2014) menunjukkan bahwa para peserta didik mempertahankan sebagian besar dari apa yang mereka dengar, lihat dan merasa daripada apa yang hanya mereka dengar. Teknologi augmented reality menyuguhkan pembelajaran yang dapat merangsang peserta didik untuk berpikir lebih mudah dan pembelajaran di kelas dirasa lebih menyenangkan menyenangkan dibandingkan dengan pembelajaran yang tidak menggunakan media berbasis teknologi.

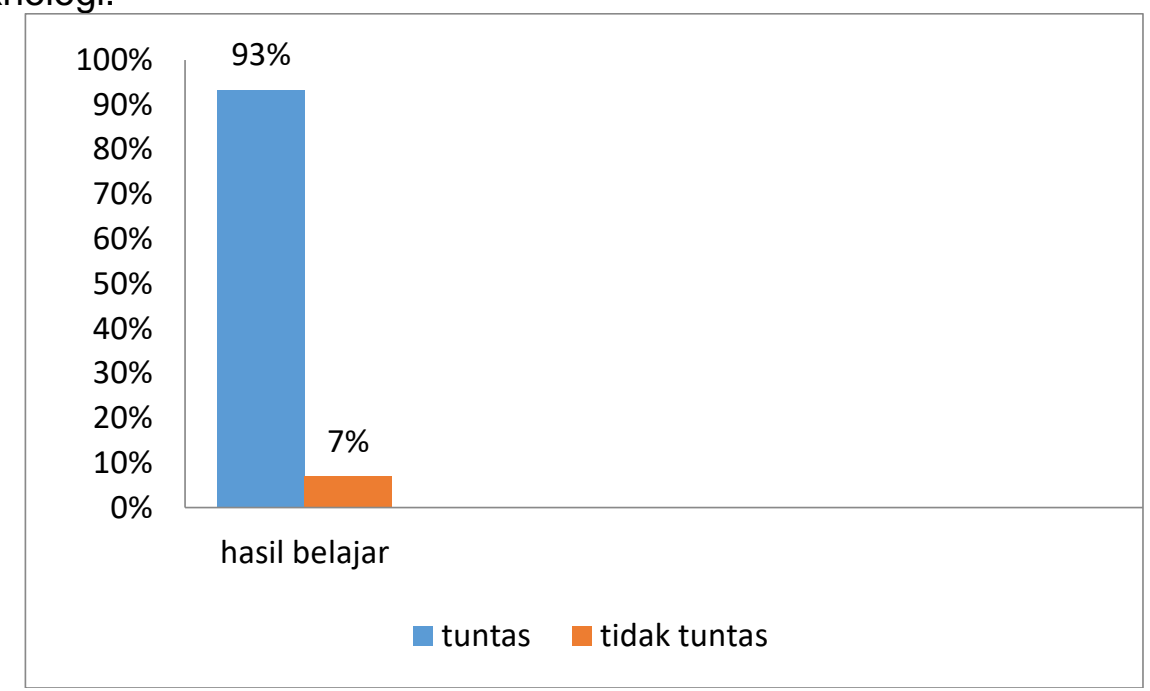

Gambar 6. Presentase Hasil Belajar Peserta didik Siklus II

\section{SIMPULAN}

Dari hasil observasi diperoleh hasil kinerja guru siklus I sebanyak 85,4\% yang menunjukkan kriteria sangat baik, pada siklus II sebanyak 93,7\% dengan kriteria sangat baik. Hasil belajar siswa pada siklus I sebanyak 18 orang atau $60 \%$ siswa yang tuntas dan pada siklus II sebanyak 28 atau 93,3\% siswa yang tuntas/mencapai KKM, sehingga dapat disimpulkan bahwa penggunaan teknologi Augmented Reality dapat meningkatkan kinerja guru dan hasil belajar siswa dalam pembelajaran. Siswa menjadi lebih bersemangat dalam mempelajari pelajaran IPS dan tidak merasa bosan ketika mendapatkan materi mengenai sejaran yang penuh dengan teks hafalan mengenai tokoh kepahlawanan. Rekomendasi bagi peneliti selanjutnya adalah peneliti dapat menambahkan variasi gambar pahlawan agar gambar pahlawan lebih bervariasi. 
Selain itu dapat juga ditambahkan gambar 3D agar media terlihat lebih menarik. Bagi guru pengajar hendaknya sebelum pembelajaran dimulai guru memberikan pengarahan yang mudah dipahami oleh siswa dalam penggunaan teknologi augmented reality serta mengecek kembali media yang akan digunakan siswa sehingga proses pembelajaran dapat berlangsung dengan lancar dan siswa dapat dengan mudah memahami pembelajaran.

\section{DAFTAR PUSTAKA}

Billinghurst, M., Kim, G. (2007). Interaction Design for Tangible Augmented reality Applications. Emerging Technolofy of Augmented reality: Interfaces and Design, Idea Group Inc, hal 261-279.

Gardiner, dkk. (2017). Era Disrupsi Peluang dan Tantangan Perguruan Tinggi Indonesia. Jakarta: Akademi Ilmu Pengetahuan Indonesia.

Ode, E. (2014). "Impact of Audio Visual (AVs) Resources on Teaching and Teaching in Some Selected Private Secondary School in Makurdi". IMPACT: Internasional Journal of Research in Humanitis, Arts, and Literature (IJRHAL). Volume 2.

Padmini dan Tyagita. (2015). Teknologi Pendidikan Sebagai Pembelajaran Kompetitif Untuk Meningkatkan Prestasi Siswa: Studi Kasus di Salah Satu SMA di Salatiga. Prosiding Seminar Nasional Indonesia.

Rochmah, E., \& Labudasari, E. (2018). Prosiding Seminar Nasional Universitas Muhammadiyah Purwokerto. Penggunaan Media Berbasis Teknologi Augmented Reality Bermuatan Wawasan Kebangsaan pada Siswa Sekolah Dasar (pp. 80-87). Purwokerto: UMP Press.

Triyanto, dkk. (2013). "Peran Kepemimpinan Kepala Sekolah Dalam Pemanfaatan Media Pembelajaran Sebagai Upaya Peningkatan Kualitas Proses Pembelajaran". Jurnal Teknologi Pendidikan. Vol 1, No 2. (hal 226-238).

Wena, M. (2014). Stategi Pembelajaran Inovatif Kontemporer Suatu Tinjauan Konseptual Operasional. Jakarta: Bumi Aksara. 